\title{
A tail length modifier gene discovered in the Japanese wild mice (Mus musculus molossinus)
}

\author{
Atsushi Fujimoto, Nobuyuki BabA ${ }^{1)}$ and Noboru Wakasugi ${ }^{2)}$ \\ Laboratory of Animal Genetics, School of Agriculture, \\ Nagoya University, Chikusa-ku, Nagoya 464-01
}

(Received 1 November 1990)

\begin{abstract}
The presence of the $t$ haplotypes in strains derived from the Japanese wild mice (Mus musculus molossinus) was investigated. Crosses between the $T /+$ heterozygous short tailed mice and five normal tailed molossinus strains (MOLANJ, MOA, MOL-NEM, MOM and Mns) produced no tailless mice, indicating that these strains possess no $t$ haplotype. In contrast, tailless mice were produced by a cross between the $T /+$ heterozygotes and a MOL-NIS strain. Mating experiments showed that the tailless character was due to an interaction between the $T$ gene and an autosomal recessive gene carried by the MOL-NIS strain that expresses the short tail character under the homozygous condition. We have tentatively named this gene brachyury-interacting tail length modifier (btm). It remains to be investigated whether the $\mathrm{btm}$ gene is located in the $t$ complex region or in the other locus.
\end{abstract}

\section{INTRODUCTION}

The $t$ complex in the mouse is a region on the proximal portion of chromosome 17. In this region several dominant $(T)$ alleles and numerous recessive $t$ haplotypes have been found. The $t$ complex is a segment of $12-15 \mathrm{cM}$ consisting of many genes, i.e., $t c t$ ( $t$-complex tail length modifier), $t c l$ ( $t$-complex lethality), $T c d$ ( $t$-complex distorter), Tcr ( $t$-complex responder), $t c s$ ( $t$-complex sterility), Tcp ( $t$-complex protein) and so on (Bennett, 1975; Artzt et al., 1982; Klein et al., 1982; Silver et al., 1983; Artzt, 1984; Lyon, 1984; Silver, 1985; Lyon, 1986; Silver \& Remis, 1987). Thus strictly speaking, the genotype expressing the tailless character is T/tct. Moreover, recombination is suppressed within the entire $t$ complex owing to the existence of at least four nonoverlapping inversions in this region (Shin et al., 1984; Herrmann et al., 1986; Hammer et al., 1989).

Many kinds of $t$ haplotypes have been found in the wild mice of Europe and the United States (Lewontin et al., 1960; Guenet et al., 1980; Klein et al., 1984; Figueroa et al., 1988; Erhart et al., 1989). But there are only a few reports

1) Present address: Toxicology Laboratory Reseach Center, Mitubishi-kasei Corporation Reseach Center, 1000-Kamoshida-cho, Midori-ku, Yokohama 227, Japan.

2) Present address: Laboratory of Animal Reproduction, School of Agriculture, Nagoya University, Chikusa-ku, Nagoya 464-01, Japan. 
about the $t$ haplotype of the Japanese wild mice (Tutikawa, 1955; Sakaizumi, 1989).

Our laboratory maintains several inbred strains derived from the Japanese wild mice $M . m$. molossinus (hereafter these strains being referred to as molossinus strains). The presence of the $t$ haplotypes in these molossinus strains was investigated, and one of them (MOL-NIS strain) produced tailless mice when crossed to the $T /+$ heterozygous short tailed mice. Almost all of the tailless
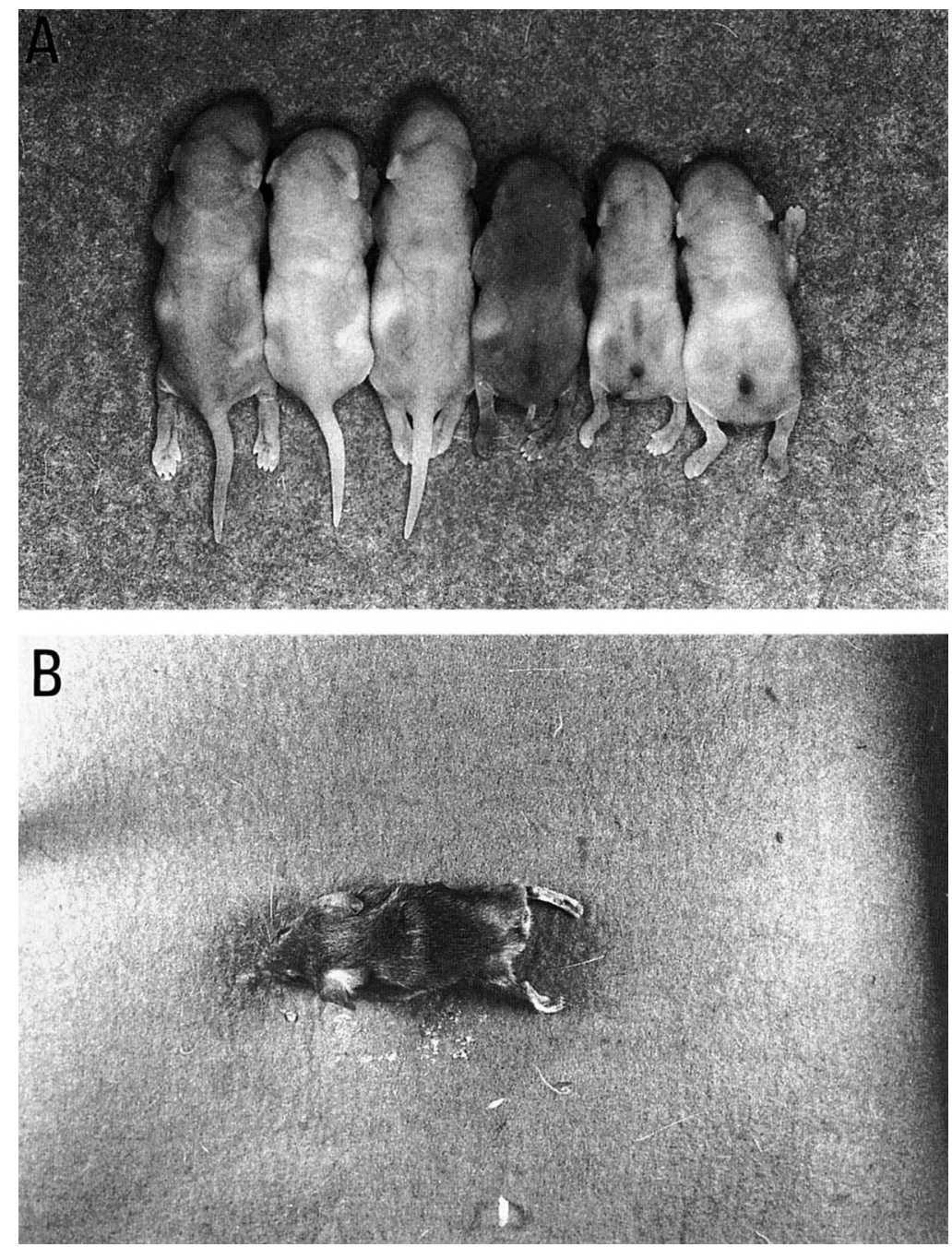

Fig. 1. A: New born mice from the cross between a $T /$ theterozygote and a MOL-NIS mouse (three on the left, normal; three on the right, tailless). A black spot on the lumbosacral region of tailless young is a blood blister. B: A tailless mouse from the cross between a $T /$ theterozygote and a MOL-NIS mouse, showing paralysis of the hind-limbs (60 days after birth). 
offspring had a blood blister on the lumbosacral area and showed paralysis of hind-limbs. Most of them died shortly after birth. A few fortunate survivors continued to show paralysis of hind-limbs and died around the age of 60 days (Fig. 1).

In the present study, the genetical analysis was performed on the factor carried by the MOL-NIS strain that influences the tail length.

\section{MATERIALS AND METHODS}

1. Mice

The strains used in the present study were C57BL/6Nga, Tw32, MOL-ANJ, MOA, MOL-NEM, MOM, Mns and MOL-NIS. Strain C57BL/6Nga was introduced from Kyoto University in 1964 and has been maintained in our laboratory. Strain Tw32 (genotype: $T / t^{w 32}$ ) was originated from the hybrids between C57BL/ $6 \mathrm{Nga}$ and a mouse with the genotype of $T / t^{w 32}$ introduced from Tohoku University, and has progressed to the 8th generation of brother-sister matings at present. Strains MOL-ANJ, MOA, MOL-NEM, MOM, Mns and MOL-NIS were derived from the Japanese wild mice. Their breeding history is given in Table 1. The $T /+$ heterozygous short tailed mice were obtained by crossing strains Tw32 ( $T /$ $\left.t^{w 32}\right)$ and C57BL/6Nga $(+/+)$. This cross produced two kinds of offspring, i.e., short tail $(T /+)$ and normal tail $(+/$ ws2 $)$. The former showed various phenotypes from near tailless to near normal. Therefore only those that showed a distinct short tail character were chosen and used for mating experiments. Hereafter these short tailed mice are referred to as st $(T /+)$ testers.

Table 1. Origin and breeding history of molossinus strains used in the present study

\begin{tabular}{llll}
\hline \multirow{2}{*}{ Strain } & \multicolumn{2}{c}{ Capturing } & Inbreeding generation \\
\cline { 2 - 3 } & \multicolumn{1}{c}{ Locality } & Year & 35 \\
\hline MOL-ANJ* & Anjo, Aichi & 1967 & 59 \\
MOA* & Anjo, Aichi & 1967 & 51 \\
MOM & Nagoya, Aichi & 1972 & 30 \\
MOL-NEM & Nemuro, Hokkaido & 1975 & 22 \\
MOL-NIS & Nishio, Aichi & 1980 & 13 \\
Mns & Nishio, Aichi & 1983 & \\
\hline
\end{tabular}

* MOL-ANJ and MOA are sublines separated from each other at the 19th generation of inbreeding.

\section{Measurement of the head-body and tail length}

Mice were anethetized with diethyl ether and the head-body and tail lengths were measured using a caliper. The head-body length was from the nose tip to the anus, and the tail length was from the anus to the tail end. 


\section{RESULTS}

\section{Survey for t haplotypes}

Table 2 shows the results of mating expriments between st $(T /+)$ testers and 6 molossinus strains. The cross between st $(T /+)$ testers and strain MOL-NIS produced tailless offspring, some of which showed blood blisters on the lumbosacral area, as mentioned previously. The crosses between st $(T /+)$ testers and remaining 5 molossinus strains produced no tailless offspring.

Table 2. Segregation of tail characters among offspring from the crosses of st $(T /+)$ testers and molossinus strains

\begin{tabular}{|c|c|c|c|c|c|c|}
\hline \multirow{2}{*}{\multicolumn{2}{|c|}{ 우 $\stackrel{\text { Cross }}{\times}$ 令 }} & \multicolumn{3}{|c|}{$\begin{array}{l}\text { No. of offspring* } \\
\text { with the phenotype of }\end{array}$} & \multirow{2}{*}{$\begin{array}{l}\text { Expected } \\
\text { segregation } \\
\text { ratio** }\end{array}$} & \multirow[t]{2}{*}{$\chi^{2}$-test } \\
\hline & & $\mathrm{tl}$ & st & nt & & \\
\hline st $(T /+)$ & $\times$ MOL-ANJ & 0 & 37 & 46 & $0: 1: 1$ & $\mathrm{P}>0.30$ \\
\hline st $(T /+)$ & $\times$ MOA & 0 & 8 & 11 & $0: 1: 1$ & $\mathrm{P}>0.30$ \\
\hline st $(T /+)$ & $\times \mathrm{MOM}$ & 0 & 10 & 12 & $0: 1: 1$ & $\mathrm{P}>0.70$ \\
\hline st $(T /+)$ & $\times$ MOL-NEM & 0 & 32 & 27 & $0: 1: 1$ & $\mathrm{P}>0.50$ \\
\hline st $(T /+)$ & $\times$ MOL-NIS & 47 & 0 & 54 & $1: 0: 1$ & $\mathrm{P}>0.30$ \\
\hline st $(T /+)$ & $\times \mathrm{Mns}$ & 0 & 35 & 25 & $0: 1: 1$ & $\mathrm{P}>0.10$ \\
\hline
\end{tabular}

* Tailless offspring (tl) were distinguished at birth and distinction between short tail (st) and normal tail (nt) was made at weaning.

** Based on the assumption that strain MOL-NIS has a $t$ haplotype under the homozygous condition and the other 5 strains have no $t$ haplotype.

These results suggest the presence of a $t$ haplotype in strain MOL-NIS and its absence in the other 5 strains. However, the short tail offspring from the 5 molossinus strains showed variable tail lengths from near tailless to normal. Therefore the tail character was analyzed by the ratio of tail length to head-body length (hereafter this ratio being referred to as $\mathrm{T} / \mathrm{HB}$ ratio). The mean values of $\mathrm{T} / \mathrm{HB}$ ratios in strains C57BL/6, MOA, MOM and MOL-NIS strains at the ages of 20 days (weaning), 40 days and 60 days are shown in Table 3. In each strain, the values at the 3 stages of growth period did not differ significantly from each other (t-test, $\mathrm{P}>0.05$ ). Therefore, the $\mathrm{T} / \mathrm{HB}$ ratio was thought to show little change after weaning. Strains C57BL/6, MOA and MOM showed the large value and strain MOL-NIS showed the small value and the difference was significant (t-test, $\mathrm{P}<0.05)$.

Frequency distributions of C57BL/6 mice and crossbreds (Tw32 $\times$ C57BL/6) at the age of 20 days according to T/HB ratio are shown in Fig. 2. All C57BL/6 mice showed $\mathrm{T} / \mathrm{HB}$ ratios larger than 0.900 . The offspring from the crosses between strains Tw32 $\left(T / t^{w 32}\right)$ and C57BL/6(+/ + ) segregated into two groups with the border value of 0.820 , and the segregation ratio was approximately $1: 1$. 
Table 3. Ratio of tail length to head-body length (T/HB ratio) in four inbred strains of mice at 3 stages of the growth period

\begin{tabular}{lcccc}
\hline \hline \multirow{2}{*}{ Strain } & \multirow{2}{*}{$\begin{array}{c}\text { No. of } \\
\text { mice }\end{array}$} & \multicolumn{3}{c}{ T/HB ratio (mean \pm s.e.m) at the age of } \\
\cline { 3 - 5 } & & 20 days & 40 days & 60 days \\
\hline C57BL/6 & 24 & $0.962 \pm 0.005$ & $0.958 \pm 0.004$ & $0.952 \pm 0.004$ \\
MOA & 21 & $0.911 \pm 0.008$ & $0.891 \pm 0.006$ & $0.901 \pm 0.008$ \\
MOM & 20 & $0.860 \pm 0.005$ & $0.853 \pm 0.005$ & $0.865 \pm 0.005$ \\
MOL-NIS & 49 & $0.660 \pm 0.012$ & $0.654 \pm 0.014$ & $0.651 \pm 0.012$ \\
\hline
\end{tabular}
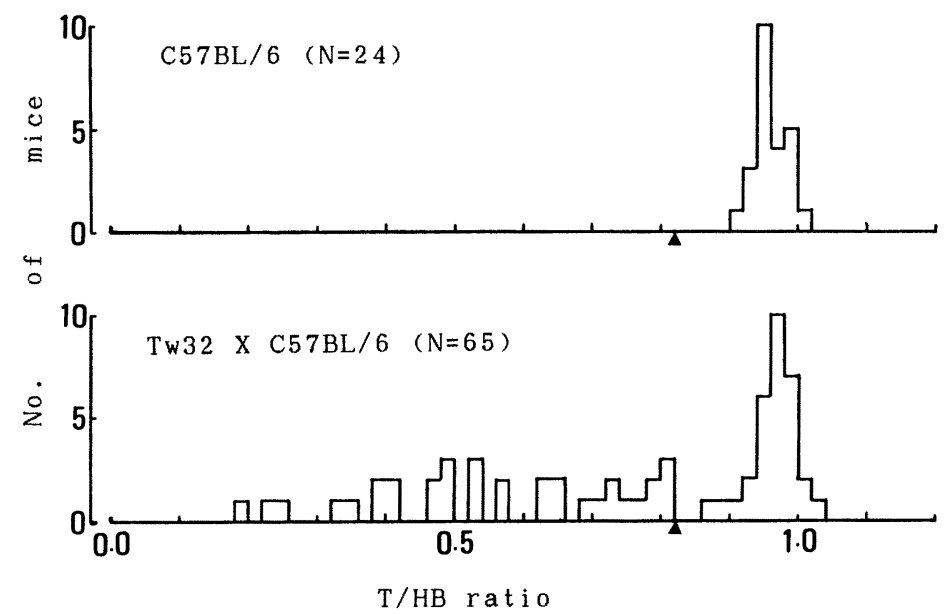

Fig. 2. Frequency distribution of C57BL/6 mice and $\mathrm{F}_{1}$ hybrids between Tw32 $\left(T / t^{w 32}\right)$ and C57BL/6 $(+/+)$ strains at the age of 20 days according to the ratio of tail length to head-body length $(\mathrm{T} / \mathrm{HB}$ ratio). A solid triangle indicates 0.820 which is regarded as the border value between short tail and normal tail.

Accordingly, one was taken as the short tail group $(T /+)$ and the other as the normal tail group $\left(+/ t^{w 32}\right)$. This distribution pattern suggests that the border value of $\mathrm{T} / \mathrm{HB}$ ratio between short tail and normal tail is 0.820 and this value is shown with a solid triangle in Figs. 2-6.

The frequency distributions for molossinus strains, MOL-ANJ, MOA and MOM, were unimodal (Fig. 3) and all individuals showed T/HB ratio higher than 0.820 except a few individuals in strain MOL-ANJ. Strains MOL-NEM and Mns showed almost the same distribution patterns as MOL-ANJ. The offspring from the crosses between st $(T /+)$ testers and 4 molossinus strains showed bimodal distributions (Fig. 4), which indicates the segregation into short tail and normal tail groups with a border value of 0.820 . The offspring from the crosses between st $(T /+)$ testers and strain Mns showed a greater variation in T/HB ratio than those from the other crosses. This is due to the variation of the short tail 

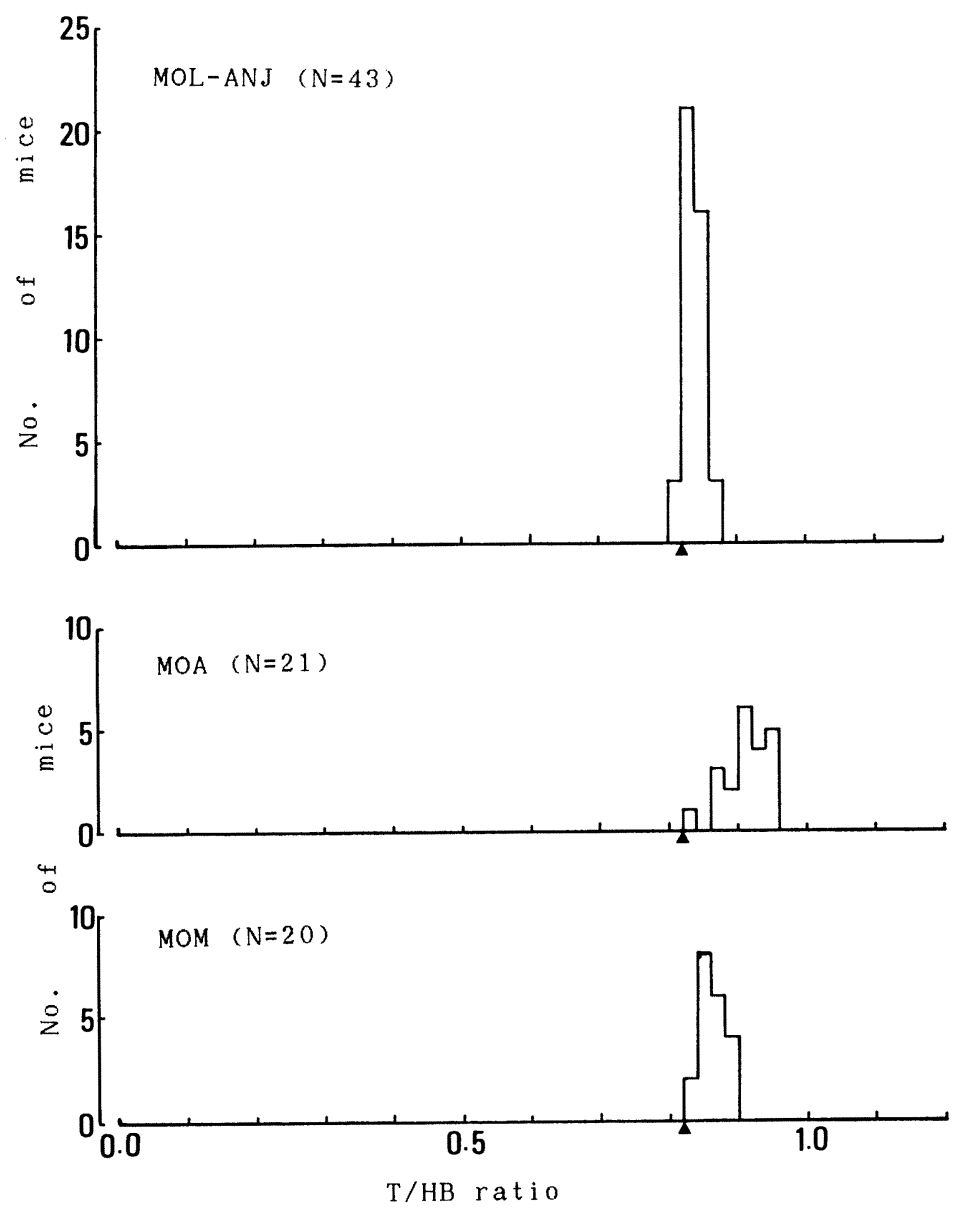

Fig. 3. Frequency distribution of MOL-ANJ, MOA and MOM mice at the age of 20 days according to the ratio of tail length to head-body length (T/HB ratio). The solid triangle indicates as in Fig. 2.

individuals, suggesting that the tail formation in the $F_{1}$ hybrids may be liable to be influenced by environmental factors in the presence of $T$ gene. When 0.820 is taken as the border value between short tail and normal tail, the following conclusions may be drawn; (1) MOL-NIS is regarded as a short tail strain, and (2) Segregation ratios of the offspring from the crosses between st $(T /+)$ testers and 5 molossinus strains (MOL-ANJ, MOA, MOL-NEM, MOM and Mns) are in agreement with the expected ratio of $1: 1$ (Table 2 ).

2. Analysis on the factors of strain MOL-NIS concerning the short tail and tailless characters

The finding that strain MOL-NIS has a gene modifying tail length led us to perform a detailed genetic analysis on this subject. The frequency distribution of 

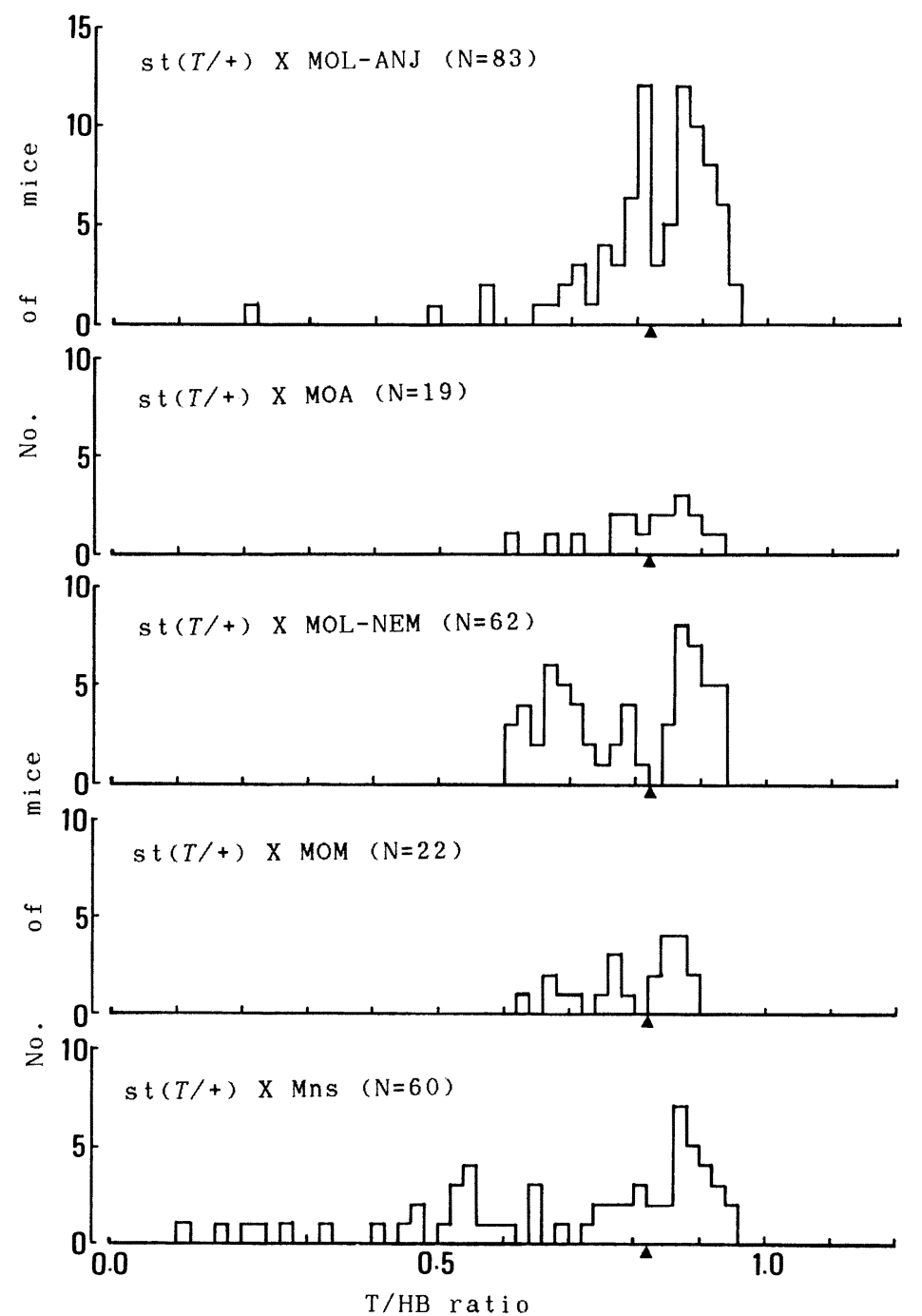

Fig. 4. Frequency distribution of $\mathrm{F}_{1}$ hybrids between st $(T /+)$ testers and five molossinus strains (MOL-ANJ, MOA, MOL-NEM, MOM and Mns) at the age of 20 days according to the ratio of tail length to head-body length ( $\mathrm{T} / \mathrm{HB}$ ratio). The solid triangle indicates as in Fig. 2.

$\mathrm{T} / \mathrm{HB}$ ratio for strain MOL-NIS is shown in Fig. 5. The values of all individuals were less than 0.780 , and this distribution patten is similar to that of the $T /+$ heterozygous short tailed mice as shown in Fig. 2. Consequently it has been confirmed that MOL-NIS is a short tail strain.

Table 4 shows the results of the mating experiments. From the reciprocal crosses of st $(T /+)$ testers and strain MOL-NIS, tailless and normal tailed mice appeared in the ratio of $1: 1$. The reciprocal crosses of st $(T /+)$ testers and $F_{1}$ 


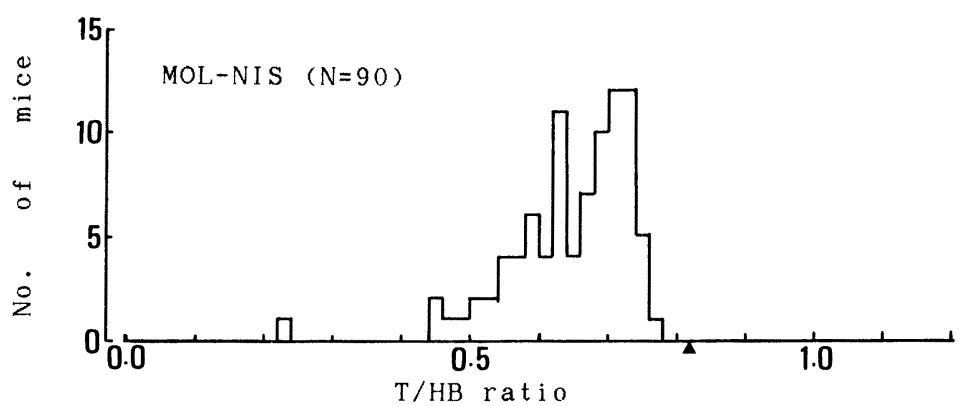

Fig. 5. Frequency distribution of MOL-NIS mice at the age of 20 days according to the ratio of tail length to head-body length (T/HB ratio). The solid triangle indicates as in Fig. 2.

Table 4. Segregation of tail characters among offspring from the crosses between st $(T /+)$ testers and strain MOL-NIS or their $\mathrm{F}_{1}$ hybrids

\begin{tabular}{lrrrrrl}
\hline \hline \multirow{2}{*}{$\begin{array}{c}\text { Cross } \\
\times\end{array}$} & \multicolumn{4}{c}{$\begin{array}{c}\text { No of offspring } \\
\text { with the phenotype of }\end{array}$} & \multirow{2}{*}{$\begin{array}{c}\text { Expected } \\
\text { segregation } \\
\text { ratio }\end{array}$} & $\chi^{2}$-test \\
\cline { 2 - 4 } & \multicolumn{1}{c}{ tl } & st & nt & & \\
\hline st $(T /+) \times$ MOL-NIS & 96 & 0 & 118 & $1: 0: 1$ & $\mathrm{P}>0.10$ \\
MOL-NIS $\times$ st $(T /+)$ & 3 & 0 & 10 & $1: 0: 1$ & $\mathrm{P}>0.05$ \\
st $(T /+) \times \mathrm{F}_{1}{ }^{*}$ & 36 & 38 & 88 & $1: 1: 2$ & $\mathrm{P}>0.50$ \\
$\mathrm{~F}_{1}{ }^{*} \times$ st $(T /+)$ & 24 & 18 & 64 & $1: 1: 2$ & $\mathrm{P}>0.05$ \\
\hline
\end{tabular}

* $\mathrm{F}_{1}$ is a normal tailed mouse from the cross between st $(T /+)$ testers and strain MOL-NIS.

The remainder of the legend is the same as in Table 2.

hybrids with a normal tail produced tailless, short tail and normal offspring in the ratio of $1: 1: 2$. The individual showing paralysis of hind-limbs and the dorsal blood blisters at birth were regarded as tailless. A distinction between short tail and normal tail was made at weaning. The individuals showing T/HB ratio less than 0.820 were regarded as short tail. Mortality of tailless offspring between birth and weaning was almost $100 \%$ and, in contrast, that of short tail and normal tail mice was negligible. The above results suggest that the tailless character is caused by an interaction between the $T$ gene and an autosomal recessive gene carried by strain MOL-NIS. At this stage, the gene symbol btm (brachyuryinteracting tail length modifier) is tentatively proposed to the recessive gene carried by strain MOL-NIS.

Next we studied the relationship between the btm gene and the short tail character. Fig. 6 shows the frequency distribution according to T/HB ratio for $F_{1}$ and $F_{2}$ hybrids and the offspring from the backcross, $F_{1} \times$ strain MOL-NIS, (referred to as $\mathrm{N}_{2}$ generation hereafter). Almost all $\mathrm{F}_{1}$ hybrids showed $\mathrm{T} / \mathrm{HB}$ ratio larger than 0.820 , so they were regarded as normal tail. The $\mathrm{F}_{2}$ and $\mathrm{N}_{2}$ hybrids showed broad continuous distributions ranging between 0.30 and 1.20. 

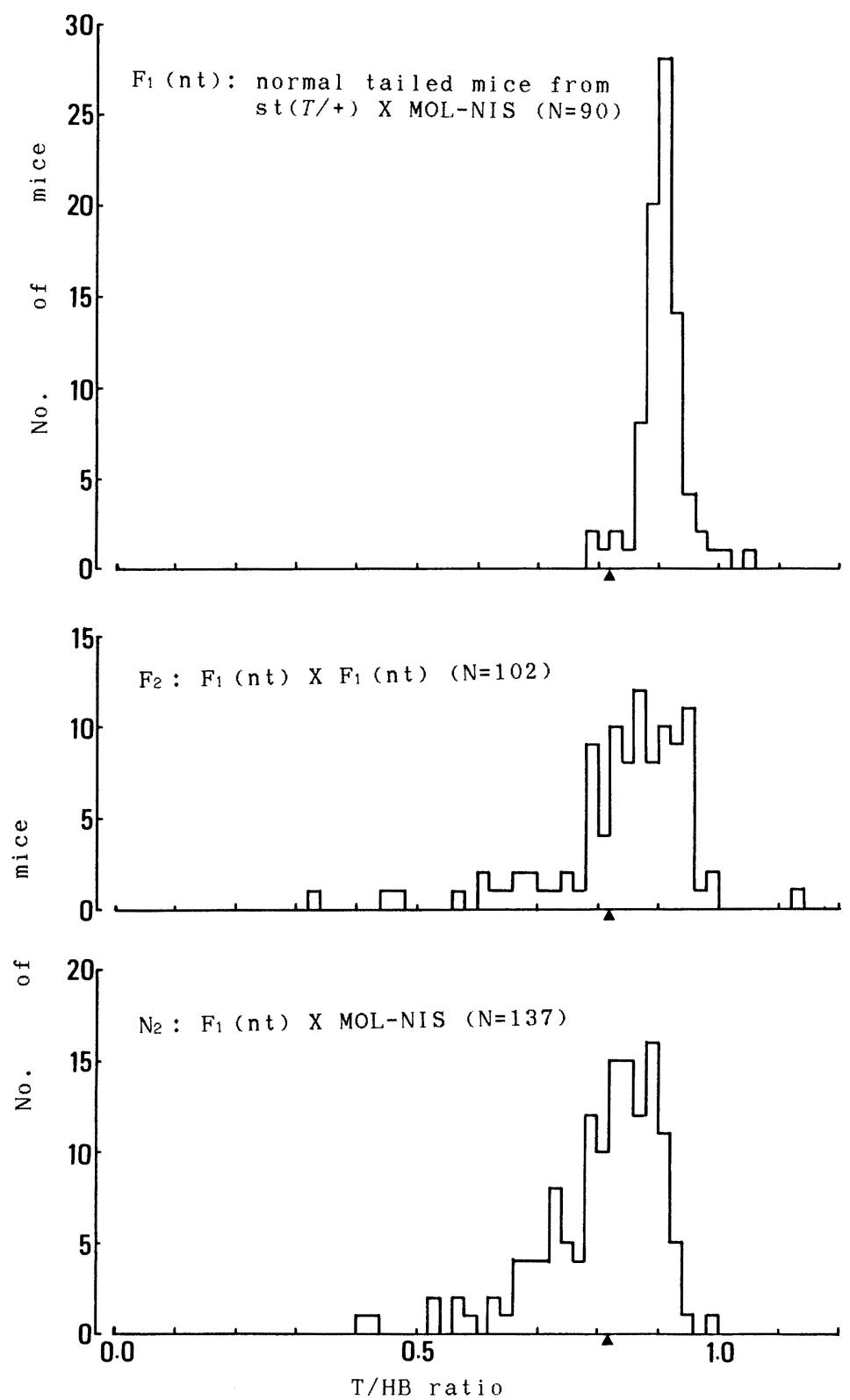

Fig. 6. Frequency distribution of $\mathrm{F}_{1}, \mathrm{~F}_{2}$ and $\mathrm{N}_{2}$ hybrids between st $(T /+)$ testers and MOL-NIS strain, at the age of 20 days according to the ratio of tail length to head-body length (T/HB) ratio). The solid triangle indicates as in Fig. 2.

In case the individuals with $\mathrm{T} / \mathrm{HB}$ ratio less than 0.820 were regarded as short tail, segregation ratio of short tail and normal tail was $1: 3$ in $\mathrm{F}_{2}$ hybrids and $1: 1$ in $\mathrm{N}_{2}$ hybrids (Table 5). The sex ratio was normal in both short tail and normal 
Table 5. Segregation of tail characters among $\mathrm{F}_{2}$ and backcross $\left(\mathrm{N}_{2}\right)$ progeny

\begin{tabular}{|c|c|c|c|c|c|c|}
\hline \multirow{2}{*}{\multicolumn{2}{|c|}{ o $\stackrel{\text { Cross }}{x}$}} & \multirow{2}{*}{$\hat{\delta}$} & \multicolumn{2}{|c|}{$\begin{array}{c}\text { No. of offspring* } \\
\text { with the phenotype of }\end{array}$} & \multirow{2}{*}{$\begin{array}{c}\text { Expected } \\
\text { segregation } \\
\text { ratio }\end{array}$} & \multirow{2}{*}{$\chi^{2}$-test } \\
\hline & & & $\mathrm{tl}$ & nt & & \\
\hline $\mathrm{F}_{1}$ & $\times$ & $\mathrm{F}_{1} * *$ & 30 & 73 & $1: 3$ & $\mathrm{P}>0.30$ \\
\hline$F_{1}$ & $\times$ & MOL-NIS & 75 & 86 & $1: 1$ & $\mathrm{P}>0.50$ \\
\hline
\end{tabular}

* The phenotype was observed at weaning (st, short tail; nt, normal tail).

** $\mathrm{F}_{1}$ is a normal tailed mouse from the cross between st $(T /+)$ testers and strain MOL-NIS.

tail groups. These results suggest that the short tail character of strain MOLNIS is controlled by an autosomal recessive gene.

However, there remained a doubt whether $\mathrm{T} / \mathrm{HB}$ ratio of 0.820 is an appropriate value to distinguish between short tail and normal tail characters, since neither $\mathrm{F}_{2}$ nor $\mathrm{N}_{2}$ hybrids showed a distinct bimodal distribution. Therefore, we investigated the relationship between the genotypes for btm gene and T/HB ratio with $\mathrm{N}_{2}$ progeny and the result is shown in Table 6 . The genotype for btm gene was determined by the progeny test with st $(T /+)$ testers.

Test individuals were regarded (1) as homozygotes (homo) when only two types of offspring, tailless and normal tail, were obtained and the number of tailless offspring was 7 or more. In this case, probability of the test individual being a homozygote is more than $99 \%(\mathrm{P}>0.99)$. The test individuals were regarded (2) as probable homozygotes (pro-homo) when the number of tailless offspring was 5 or 6 (probability of the test individual being a homozygote is more than $95 \%$ : $\mathrm{P}>0.95)$, (3) as heterozygotes (hetero) when short tail offspring was obtained, and (4) non-classifible (non-class), when only two types of offspring, tailless and normal tail, were obtained and the number of tailless offspring was less than 4 . In the last case, probability of the test individual being a homozygote is less than $95 \%$ $(\mathrm{P}<0.95)$. All of the homozygotes showed $\mathrm{T} / \mathrm{HB}$ ratios less than 0.820 and all of the heterozygotes showed T/HB ratios larger than 0.820 . This border value is the same as that distinguishing between $T /+$ heterozygous short tail mice and normal tail mice mentioned in the previous section.

\section{DISCUSSION}

The present study has clarified the following. (1) Five molossinus strains (MOL-ANJ, MOA, MOL-NEM, MOM and Mns) have no $t$ haplotype. (2) From the cross between st $(T /+)$ testers and strain MOL-NIS, tailless and normal offspring segregate in the ratio of $1: 1$. (3) This tailless character is expressed by an interaction between the $T$ gene and an autosomal reccesive gene carried by strain MOL-NIS. This gene has been tentatively named btm (brachyuryinteracting tail length modifier). (4) Homozygotes for the btm gene show a short 
Table 6. Relationship between the genotypes for btm gene and ratio of tail length to head-body length (T/HB ratio) in backcross $\left(\mathrm{N}_{2}\right)$ progeny

\begin{tabular}{|c|c|c|c|c|c|c|}
\hline \multirow{2}{*}{$\begin{array}{l}\mathrm{N}_{2} \\
\text { progeny } \\
\text { no. }\end{array}$} & \multirow{2}{*}{$\begin{array}{l}\text { No. of } \\
\text { litters }\end{array}$} & \multicolumn{3}{|c|}{ No. of offspring* } & \multirow{2}{*}{$\begin{array}{l}\text { Genotype } \\
\text { for } b t m\end{array}$} & \multirow{2}{*}{$\mathrm{T} / \mathrm{HB}$ ratic } \\
\hline & & $\mathrm{tl}$ & st & nt & & \\
\hline 1 & 1 & 7 & 0 & 2 & homo & 0.415 \\
\hline 2 & 2 & 5 & 0 & 13 & pro-homo & 0.479 \\
\hline 3 & 3 & 8 & 0 & 16 & homo & 0.695 \\
\hline 4 & 2 & 12 & 0 & 8 & homo & 0.705 \\
\hline 5 & 2 & 7 & 0 & 7 & homo & 0.707 \\
\hline 6 & 2 & 10 & 0 & 8 & homo & 0.729 \\
\hline 7 & 1 & 8 & 0 & 6 & homo & 0.735 \\
\hline 8 & 4 & 11 & 0 & 22 & homo & 0.735 \\
\hline 9 & 1 & 4 & 0 & 7 & non-class & 0.761 \\
\hline 10 & 2 & 7 & 0 & 5 & homo & 0.770 \\
\hline 11 & 2 & 6 & 0 & 6 & pro-homo & 0.777 \\
\hline 12 & 2 & 16 & 0 & 7 & homo & 0.790 \\
\hline 13 & 3 & 10 & 0 & 7 & homo & 0.792 \\
\hline 14 & 2 & 11 & 0 & 6 & homo & 0.797 \\
\hline 15 & 3 & 11 & 0 & 8 & homo & 0.804 \\
\hline 16 & 2 & 8 & 0 & 6 & homo & 0.810 \\
\hline 17 & 2 & 8 & 0 & 7 & homo & 0.812 \\
\hline 18 & 2 & 7 & 0 & 8 & homo & 0.813 \\
\hline 19 & 3 & 11 & 0 & 15 & homo & 0.814 \\
\hline 20 & 2 & 6 & 0 & 12 & pro-homo & 0.817 \\
\hline 21 & 2 & 7 & 0 & 11 & homo & 0.820 \\
\hline 22 & 1 & 3 & 3 & 6 & hetero & 0.825 \\
\hline 23 & 1 & 3 & 1 & 8 & hetero & 0.830 \\
\hline 24 & 2 & 1 & 4 & 12 & hetero & 0.837 \\
\hline 25 & 1 & 1 & 2 & 2 & hetero & 0.841 \\
\hline 26 & 1 & 2 & 1 & 4 & hetero & 0.849 \\
\hline 27 & 1 & 2 & 2 & 2 & hetero & 0.859 \\
\hline 28 & 2 & 3 & 4 & 12 & hetero & 0.869 \\
\hline 29 & 2 & 4 & 4 & 12 & hetero & 0.877 \\
\hline 30 & 1 & 2 & 1 & 6 & hetero & 0.885 \\
\hline 31 & 1 & 0 & 2 & 5 & hetero & 0.885 \\
\hline 32 & 1 & 2 & 2 & 3 & hetero & 0.890 \\
\hline 33 & 2 & 3 & 3 & 6 & hetero & 0.892 \\
\hline 34 & 1 & 0 & 4 & 7 & hetero & 0.903 \\
\hline 35 & 1 & 2 & 1 & 3 & hetero & 0.905 \\
\hline 36 & 2 & 3 & 2 & 2 & hetero & 0.912 \\
\hline 37 & 1 & 2 & 1 & 4 & hetero & 0.922 \\
\hline 38 & 1 & 2 & 1 & 0 & hetero & 0.936 \\
\hline
\end{tabular}

* Phenotypes of offspring were judged by the same method as mentioned in Table 2 (tl, tailless; st, short tail; nt, normal tail). 
tail character. (5) MOL-NIS is a short tail strain due to the homozygosity for this gene $(\mathrm{btm} / \mathrm{btm})$. It remains to be investigated whether the $\mathrm{btm}$ gene is one of $t$ haplotypes or a different gene causing a tailless character by interacting with the $T$ gene.

As for the possibility that the btm gene is one of $t$ haplotypes, we have to investigate several related characteristics of the $t$ complex. The btm homozygote is not lethal, therefore the btm gene has no $t c l$ ( $t$-complex lethality) gene. Male sterility appears in the $t c s-2 / t c s-2$ ( $t$-complex sterility-2) homozygote or $t c s-1 / t c s-1$ homozygote having tcs- 2 gene (Lyon, 1986). Since the $\mathrm{btm} / \mathrm{btm}$ males are fertile, the $\mathrm{btm}$ gene has no tcs- 2 gene. Transmission ratio distortion occurrs in Tcr ( $t$-complex responder) heterozygous males (Lyon, 1984). The segregation ratio of tailless and short tail was normal in the offspring from the crosses between female st $(T /+)$ testers and male $\mathrm{F}_{1}$ hybrids (heterozygous for btm gene), thus btm gene does not seem to possess the Tcr gene.

However, there remains a possibility that $b t m$ may be an allele of $t c t$ ( $t$-complex tail length modifier). Among numerous recessive alleles at the $t$ complex, $t^{A E 5}$ / $t^{A E 5}$ ( $t$-Albert Einstein-5) homozygote is found to be viable and shows a short tail character (Vojtiskova et al., 1976). These characteristics are similar to those of the btm homozygotes. In addition, it has been shown that $t^{A E 5}$ haplotype has the tct gene, but it has neither tcs-2 nor Tcr (Herrmann et al., 1986). Unlike the btm gene, $t^{A E 5} / t^{A E 5}$ homozygotes show poor growth, and lowered viability and fertility, moreover $T / t^{A E 5}$ being viable and tailless. However, the presence of $t^{A E 5}$ haplotype suggests a possibility that the $b t m$ gene may be an allele of the $t$ complex.

Other major factors causing tailless by interacting with the $T$ gene are the $t$-int gene and the specific genetic background. The $t$-int gene is not linked to the $t$ complex, but interacts with various kinds of $t$ complex mutations such as $T$ and $t c t$ to reduce tail length. The tailless character is expressed by the genotypes such as $(T /+, t$-int/t-int), $(T /+, t$-int $/+)$ and (tct/tct, $t$-int/t-int) (Artzt et al., 1987). However, the btm gene does not seem to be the same as the $t$-int gene, for $t$-int/ $t$-int homozygotes possess normal tail (Artzt et al., 1987). On the other hand, it is known that the effect of the $T$ gene is influenced by the genetic background. For example, $T /+$ heterozygotes are frequently complete tailless on the C57BL/ 10 or BALB/c background (Mickova \& Ivanyi, 1974; Artzt et al., 1987).

There would be little possibility that the tailless character of the crossbreds of st $(T /+)$ testers and strain MOL-NIS is due to an influence of the genetic background because of the following reasons. (1) When the tailless character is caused by the effect of the C57BL/10 or BALB/c background, $T /+$ individuals are not always tailless (Mickova \& Ivanyi, 1974; Artzt et al., 1987). (2) Genes from the three strains are mixed in the tailless offspring from the crosses between st $(T /+)$ testers and strain MOL-NIS.

DNA probes specific to $t$ haplotypes such as T66 and Tcp-1 have been exploited 
by the molecular genetic technique (Rohme et al., 1984; Fox et al., 1984). Our preliminary RFLPs (Restriction fragment length polymorphisms) analysis using T66 and Tcp-1 probes suggested that the btm gene was different from known $t$ haplotypes. However, there still remains a possibility that the $b t m$ gene may be a new allele of the $t$ complex. Linkage tests are now being performed with biochemical and immunological marker genes, results of which will clarify whether the btm gene is located in the $t$ complex or in the other locus.

We thank Professor T. Tomita, Dr. T. Namikawa, Dr. Y. Kawamoto and members of the Laboratory of Animal Genetics, Nagoya University, for their suggestions and criticisms. We are also grateful to Professor K. Moriwaki (National Institute of Genetics) and Dr. Y. Harada (National Institute of Radiological Sciences) for their assistance with the RFLPs analysis.

\section{REFERENCES}

ARTZT, K. (1984) Gene mapping within the $T / t$ complex of the mouse. III: $t$-Leathal genes are arranged in three clusters on chromosome 17. Cell 39, 565-572.

Artzt, K., Cookingham, J. and Bennett, D. (1987) A new mutation ( $t$-int) interacts with the mutations of the mouse $T / t$ complex that affect the tail. Genetics 116, 601-605.

Artzt, K., McComick, P. and Bennett, D. (1982) Gene mapping within $T / t$ complex of the mouse. I: $t$-Leathal genes are nonallelic. Cell 28, 463-470.

BennetT, D. (1975) The T-locus of the mouse. Cell 6, 441-454.

Erhart, M. A., Phillips, S. J., Bonhomme, F., Boursot, P., Wakeland, E. K. and Nadeau, J. H. (1989) Haplotypes that are mosaic for wild-type and $t$-complex-specific alleles in wild mice. Genetics 123, 405-415.

FigueroA, F., Neufeld, E., Ritte, U. and Klein, J. (1988) $t$-Specific DNA polymorphisms among wild mice from Israel and Spain. Genetics 119, 157-160.

Fox, H. S., Martin, G. R., Lyon, M. F., Herrmann, B., Frischauf, A-H., Lehrach, H. and Silver, L. M. (1985) Molecular probes define different regions of the mouse $t$ complex. Cell 40, $63-69$.

Fox, H. S., Silver, L. M. and Martin, G. R. (1984) An alpha globin pseudogene is located within the mouse $t$ complex. Immunogenetics 19, 125-130.

Guenet, J-L., Condamine, H., Gaillard, J. and JacoB, F. (1981) $t^{w P a-1}, t^{w P a-2}, t^{w P a-3}$, : three new $t$ haplotypes in the mouse. Genet. Res. 36, 211-217.

Hammer, M. F., Schimenti, J. and Silver, L. M. (1989) Evolution of mouse chromosome 17 and the origin of inversions associated with $t$ haplotypes. Proc. Natl. Acad. Sci. USA 86, 3261-3265.

Herrmann, B., Bucan, M., Mains, P. E., Frischuf, A-H., Silver, L. M. and Lehrach, H. (1986) Genetic analysis of the proximal portion of the mouse $t$ complex: evidence for a second inversion within $t$ haplotypes. Cell 44, 469-476.

Klein, J., FigueroA, F. and Klein, D. (1982) H-2 haplotypes, genes, and antigens: second listing. Non-H-2 loci on chromosome 17 . Immunogenetics 16, 285-317.

Klein, J., Spipos, P. and FigueroA, F. (1984) Polymorphism of $t$-complex gene in European wild mice. Genet. Res. 44, 39-46.

Lewontin, R. C. and Dunn, L. C. (1960) The evolutionary dynamics of a polymorphism in the house mouse. Genetics 45, 705-722.

LyON, M. F. (1984) Transmission ratio distortion in mouse $t$-haplotypes is due to multiple distorter genes acting on a responder locus. Cell 37, 621-628.

Lyon, M. F. (1986) Male sterility of the mouse $t$-complex is due to homozygosity of the distorter 
genes. $\quad$ Cll 44, 357-363.

Mickova, M. and Ivanyi, P. (1974) Sex-dependent and $H$-2-linked influence on expressivity of the brachyury gene in mice. J. Hered. 65, 369-372.

Rohme, D., Fox, H., Herrmann, B., Frischauf, A-M., Edstrom, J-E., Mains, P., Silver, L. M. and LeHRACH, H. (1984) Molecular clones of the mouse $t$ complex derived from microdissected metaphase chromosomes. Cell 36, 783-788.

SaKaizumi, M. (1989) $t$-Chromosomes found in East Asiatic wild mice, M. m. molossinus and $M$. $m$. casteneus. Mouse News Letter 84, 119-120.

Shin, H-S., BennetT, D. and ArtZT, K. (1984) Gene mapping within the $T / t$ complex of the mouse. IV: The inverted MHC is intermingled with several $t$-lethal genes. Cell 39, 573-578.

Silver, L. M. (1985) Mouse $t$ haplotypes. Ann. Rev. Genet. 19, 179-208.

Silver, L. M. and Remis, D. (1987) Five of the nine genetically defined regions of mouse $t$ haplotypes are involved in transmission ratio distortion. Genet. Res. 49, 51-56.

Silver, L. M., Uman, J., Danska, J. and Garrels, J. I. (1983) A diversified set of testicular cell proteins specified by genes within the mouse $t$ complex. Cell 35, 35-45.

TutikawA, K. (1954) Further studies on $T$ locus in the Japanese wild mouse, Mus musculus molossinus. Ann. Rep. Nat. Inst. Genet. 5, 13-15.

Vojtiskova, M., Viklicky, V., Voracova, B., Lewis, S. E. and Glucksohn-Waelsh, S. (1976) The effects of a $t$-allele $\left(t^{A E 5}\right)$ in the mouse on the lymphoid system and reproduction. J. Embryol. Exp. Morph. 36, 443-451. 